Pediat. Res. 6: 693-700 (1972)

Acetylcholine neonate atropine prematurity

bradykinin sympathetic nervous system

ductus arteriosus

\title{
The Pattern and Mechanisms of Response to Oxygen by the Ductus Arteriosus and Umbilical Artery
}

\author{
Ingrid Oberhänsli-Weiss, Mighael A. Heymann ${ }^{[39]}$, Abraham M. Rudolph, and \\ Kenneth L. Melmon
}

Cardiovascular Research Institute and Departments of Pediatrics, Physiology and Pharmacology, University of California San Francisco, San Francisco, California, USA

\section{Extract}

Response of the ductus arteriosus and umbilical artery to changes in oxygen tension, to acetylcholine, and to sympathetic and parasympathetic blocking agents was studied in vitro in isolated rings obtained from 22 fetal lambs of 98- to 147-day gestation.

After stabilization of tension at a baseline level $(0.3-0.7 \mathrm{~g})$ in a $\mathrm{P}_{\mathrm{O}_{2}}$ environment of $35-45 \mathrm{~mm} \mathrm{Hg}$, both increase of the $\mathrm{P}_{\mathrm{O}_{2}}$ to $550 \mathrm{~mm} \mathrm{Hg}$ and decrease of the $\mathrm{P}_{\mathrm{O}_{2}}$ to $8 \mathrm{~mm} \mathrm{Hg}$ of the bathing solution produced constriction. The mean maximal tension developed by the ductus arteriosus. was $3.91 \mathrm{~g}$ at high $\mathrm{P}_{\mathrm{O}_{2}}$ and $3.87 \mathrm{~g}$ at low $\mathrm{P}_{\mathrm{O}_{2}}$. The increase in maximal tension developed with advancing gestation was also similar at both high and low $\mathrm{P}_{\mathrm{O}_{2}}$.

At $\mathrm{P}_{\mathrm{O}_{2}}$ levels of 8-550 $\mathrm{mm} \mathrm{Hg}$, acetylcholine produced a further increase in tension, whereas bradykinin only produced an increase in tension at high $\mathrm{P}_{\mathrm{O}_{2}}$. Alpha and beta sympathetic blockade had no effect on the constrictor response to oxygen. Atropine relaxed the ductus arteriosus and umbilical artery at both high and low $\mathrm{P}_{\mathrm{O}_{2}}$ levels; the degree of relaxation was related to drug concentration. Acetylcholinesterase also relaxed the ductus arteriosus constricted by oxygen. The cholinesterase inhibitor, edrophonium, produced ductus constriction at $\mathrm{P}_{\mathrm{O}_{2}}$ of $35-45 \mathrm{~mm} \mathrm{Hg}$ with little further effect from high $\mathrm{P}_{\mathrm{O}_{2}}$. The constrictor effect of high or low $\mathrm{P}_{\mathrm{O}_{2}}$ on the ductus arteriosus and umbilical artery seems to be mediated through release of acetylcholine.

\section{Speculation}

Postnatal closure of the ductus arteriosus is effected by an increase in oxygen environment. This is probably mediated by the release of acetylcholine. Inability of many premature infants to close effectively the ductus arteriosus is therefore probably due to an inability to synthesize or release adequate amounts of acetylcholine rather than to lack of the mechanism of muscular constriction.

Parasympathetic blocking agents may be of use in preventing constriction of the ductus arteriosus in infants with congenital heart disease who are dependent on its patency for survival. 


\section{Introduction}

The ductus arteriosus, a wide channel approximating the aortic diameter in the fetus, is functionally obliterated by means of constriction of its wall within a few hours after birth. The exact mechanism responsible for this constriction is as yet not known. However, it is well known that the ductus constricts when exposed to an elevation of oxygen tension, either by increasing the $\mathrm{Po}_{2}$ of blood in the intact animal, or by raising the $\mathrm{Po}_{2}$ in the environment of the isolated vessel $[2,4,7,8,11,13,14,17,19,20]$. The umbilical artery shows a similar response on exposure to oxygen $[4,9]$. The rise in arterial $\mathrm{Po}_{2}$ which occurs after birth following ventilation has therefore been thought to be important in causing ductal and umbilical arterial constriction. The isolated ductus arteriosus and umbilical artery are also constricted by norepinephrine and epinephrine, and by acetylcholine, but the role of the autonomic nervous system and of vasoactive agents such as catecholamines and peptides in normal closure is uncertain $[1,5,6,14,16,17]$.

The possibility that the effects of oxygen could be produced through release of a chemical mediator has been entertained by several investigators. Bradykinin is released into the arterial circulation of fetal lambs when they are ventilated with oxygen, and the possibility that the effect of oxygen on the ductus is mediated through bradykinin has been considered [10]. The role of acetylcholine release by parasympathetic stimulation and of catecholamine release in producing the constrictive response to oxygen has been studied by examining the effects of specific pharmacological blocking agents on the ductus arteriosus and umbilical artery.

Kovalčik [14] has shown that constriction of isolated lamb ductus arteriosus on exposure to oxygen was not prevented by blockade with phenoxybenzamine or atropine. These studies were performed in ductal strips from fetal lambs of 78- to 144-day gestation, but gestational ages were not specified in the studies in which specific drug responses were examined. Recently we showed that the constrictor response to oxygen of the fetal lamb ductus arteriosus increases with advancing gestational age [17]. We were therefore concerned that the effects of pharmacologic agents on the oxygen response might not have been evident if the tissue examined was obtained from premature lambs. Furthermore response of the ductus arteriosus to varying concentrations of pharmacologic agents was not studied. We have therefore reexamined the pattern of response of the ductus arteriosus and umbilical artery to changing levels of $\mathrm{Po}_{2}$, and, in order to define the mechanisms involved, we have evaluated the influence on the oxygen response of sympathetic and parasympathetic blocking agents.

\section{Materials and Methods}

Twenty-two fetal lambs which weighed $780-4900 \mathrm{~g}$ and were of 98- to 147-day gestational age [3] were delivered through a midline abdominal incision in the ewe after low spinal analgesia with $20 \mathrm{mg}$ tetracaine $\mathrm{HCl}$ [23]. The fetus was prevented from breathing by the immediate placement of a saline-filled rubber glove over its head, and it was killed by rapid exsanguination. Two concentric rings $2 \mathrm{~mm}$ thick were cut from the midsection of the ductus arteriosus and from one umbilical artery $5-10 \mathrm{~cm}$ from the fetal abdominal wall. The two ductal rings were suspended in series in an isolated organ-tissue bath [24] containing Tyrode's solution ( $\mathrm{NaCl}, 8 \mathrm{~g} ; \mathrm{KCl}, 0.2 \mathrm{~g} ; \mathrm{CaCl}_{2}, 0.2 \mathrm{~g} ; \mathrm{MgCl}_{2}$. $6 \mathrm{H}_{2} \mathrm{O}, 0.1 \mathrm{~g} ; \mathrm{NaH}_{2} \mathrm{CO}_{3}, 1 \mathrm{~g} ; \mathrm{NaH}_{2} \mathrm{PO}_{4} \cdot \mathrm{H}_{2} \mathrm{O}, 0.05 \mathrm{~g}$; dextrose, $1 \mathrm{~g}$; and distilled water to $1000 \mathrm{ml}$ ). The two umbilical arterial rings were similarly suspended in a second bath. The two organ baths were immersed in a constant temperature water bath at $38^{\circ}$. The rings, both ductal and umbilical arterial, were attached to a glass hook at the base of the bath and suspended from an isometric linear force displacement transducer [25]. Changes in tension were recorded on a direct writing polygraph [26]. A change of $0.1 \mathrm{~g}$ in tension produced a linear displacement of $20 \mu \mathrm{m}$ and the recorder was calibrated so that this produced a deflection of $2 \mathrm{~mm}$. In all preparations, initial tension was set at about $0.5 \mathrm{~g}$ but the range of this tension in individual experiments was $0.3-0.7 \mathrm{~g}$. Gas mixtures containing $5 \% \mathrm{CO}_{2}$ with varying concentrations of $\mathrm{O}_{2}$ and $\mathrm{N}_{2}$ were bubbled through copper tubing into the organ bath and also into a reservoir bottle which was used for fluid replacement to each bath. Small samples of the bathing solution were repeatedly withdrawn from the organ bath and $\mathrm{pH}, \mathrm{PCO}_{2}$ and $\mathrm{Po}_{2}$ were measured, using microelectrodes and blood gas analyzer [27]. Changes in $\mathrm{Po}_{2}$ levels ranged from 8 to 550 $\mathrm{mm} \mathrm{Hg}$, whereas $\mathrm{pH}$ and $\mathrm{PCO}_{2}$ were maintained at a relatively constant level. $\mathrm{PCO}_{2}$ varied from 30 to $40 \mathrm{~mm}$ $\mathrm{Hg}$ and $\mathrm{pH}$ from 7.35 to 7.45 in the whole series of experiments; however, within any individual experiment there was a smaller variation of $5 \mathrm{~mm} \mathrm{Hg} \mathrm{PcO}_{2}$ and 0.05 units of $\mathrm{pH}$.

A period of $2 \mathrm{hr}$ was allowed to elapse while the rings were suspended in Tyrode's solution equilibrated

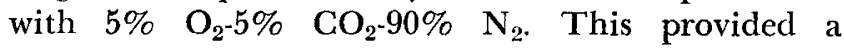


$\mathrm{Po}_{2}$ level in the bathing solution ranging, in individual experiments, from 35 to $45 \mathrm{~mm} \mathrm{Hg}$. After this period, the ring tensions were constant in all preparations and this was accepted as the baseline tension since previous pilot studies had shown that the ductus arteriosus was maximally relaxed at this level of $\mathbf{P o}_{2}$.

An oxygen dose response curve was obtained in 8 preparations by increasing the $\mathrm{Po}_{2}$ stepwise by increments of about $25 \mathrm{~mm} \mathrm{Hg}$ to a level of $150 \mathrm{~mm} \mathrm{Hg}$ and then by increments of about $200 \mathrm{~mm} \mathrm{Hg}$ to a maximal $\mathrm{Po}_{2}$ level of $450-550 \mathrm{~mm} \mathrm{Hg}$. In some of these studies, when maximal constriction had been accomplished, the $\mathrm{Po}_{2}$ was decreased in similar steps to the baseline level of $35-45 \mathrm{~mm} \mathrm{Hg}$. After stabilization at that level, it was further reduced to the lowest level attainable with $5 \% \mathrm{CO}_{2}-95 \% \mathrm{~N}_{2}$; this ranged from 8 to $20 \mathrm{~mm}$ $\mathrm{Hg}$ in different experiments. These changes in $\mathrm{Po}_{2}$ from high to low levels were repeated several times in five studies. In nine other experiments, after initial stabilization at a $\mathrm{Po}_{2}$ of $35-45 \mathrm{~mm} \mathrm{Hg}$, the order was reversed and $\mathrm{Po}_{2}$ was first decreased to the lowest level and then subsequently increased to $450-550 \mathrm{~mm} \mathrm{Hg}$. Maximum constrictor responses to changes in $\mathrm{Po}_{2}$ level could be elicited for periods of at least $12 \mathrm{hr}$ after the rings were suspended in the bath.

When maximal constriction of either the ductal or umbilical arterial rings had been achieved either at high or low $\mathrm{Po}_{2}$, the effects of several drugs on the constrictor response were examined. These studies were performed in order to determine whether the ductus responded in a manner similar to that previously reported. In 13 studies, acetylcholine chloride [28] was added to the bath at either high $(450-550 \mathrm{~mm} \mathrm{Hg}$ ) or low $\left(8-20 \mathrm{~mm} \mathrm{Hg}\right.$ ) $\mathrm{Po}_{2}$ ranges to produce concentrations of $10^{-6}$ to $10^{-3} \mathrm{M}$. The effect of bradykinin [29] was examined in 5 studies at bath concentrations of $0.1-10.0 \mu \mathrm{g} / \mathrm{ml}$ at both high and low levels of $\mathbf{P o}_{2}$. In four studies, alpha adrenergic receptor blockade was produced by adding phentolamine methanesulfonate [30] to produce a concentration in the bath of $10^{-6_{-}}$ $10^{-3}$ M. In three preparations, beta adrenergic receptor blockade was produced by adding propranolol $\mathrm{HCl}$ [31] to produce concentrations of $10^{-6}-10^{-4} \mathrm{M}$. Dose response curves for these drugs were not, however, consistently obtained.

Parasympathetic blockade was accomplished with atropine [32] in bath concentrations of $10^{-6}-10^{-3} \mathrm{M}$ in 17 animals aged 98-147 days. Effects of atropine were examined in more detail, and dose response curves were established for the ductus arteriosus in 7 preparations at a high $\mathrm{Po}_{2}$ level and in 5 at low $\mathrm{Po}_{2}$. In the

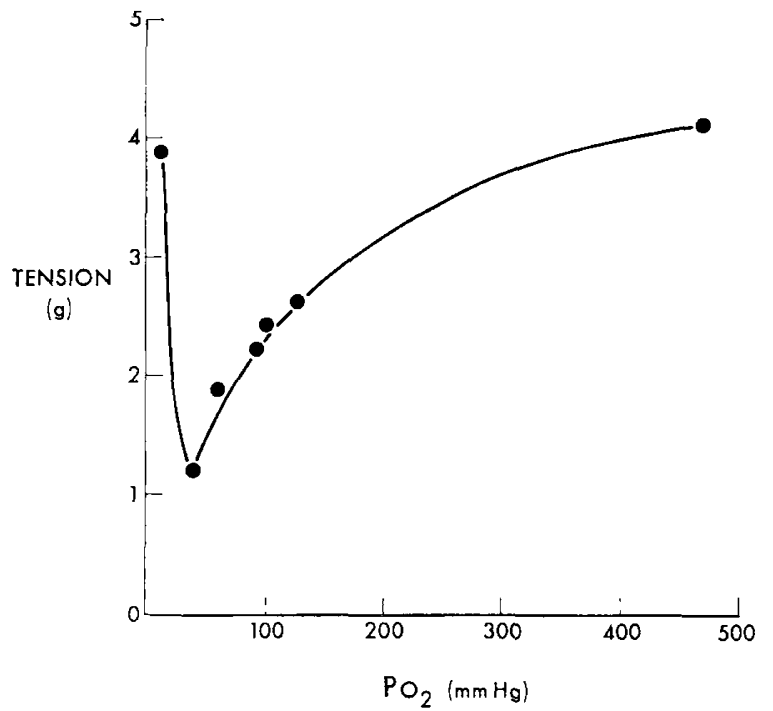

Fig. 1. Tension developed by ductal rings of $4800 \cdot \mathrm{g}$ fetal lamb successively exposed to $\mathrm{P}_{\mathrm{O}_{2}}$ of $35 \mathrm{~mm} \mathrm{Hg}, 10 \mathrm{~mm} \mathrm{Hg}$, and then increasing $\mathbf{P}_{\mathrm{O}_{2}}$ levels.

umbilical arterial studies, dose response curves were obtained in 3 preparations at high $\mathrm{Po}_{2}$ and in 4 at low $\mathrm{Po}_{2}$. In five of the ductus preparations utilizing atropine, acetylcholine was added in increasing doses to the organ bath, after maximal atropine responses had been obtained, to test for competitive inhibition. In three studies, the effect of bradykinin was similarly tested following a maximal response to atropine. The effects of acetylcholinesterase in concentrations of 0.01$10 \mu \mathrm{g} / \mathrm{ml}$ [33] and of edrophonium chloride [34] in bath concentrations of $10^{-6}-10^{-3} \mathrm{M}$ were each examined in three preparations.

\section{Results}

\section{Responses of Ductus Arteriosus and Umbilical Artery to Changes in $\mathrm{PO}_{2}$}

Responses of both ductus arteriosus and umbilical artery to variations in $\mathrm{Po}_{2}$ were slow. Response was observed 10-15 min after a change in $\mathrm{Po}_{2}$ in the bath, and the maximal response at any given $\mathrm{Po}_{2}$ level was reached only after $20-30 \mathrm{~min}$.

In all 19 preparations examined, either an increase or decrease in $\mathrm{Po}_{2}$ from the resting baseline level of $35-45 \mathrm{~mm} \mathrm{Hg}$ produced constriction of the ductus arteriosus as evidenced by an increase in tension developed. A representative oxygen response curve for one animal is shown in Figure 1.

When the ductus arteriosus was initially exposed to a low $\mathrm{Po}_{2}(8-20 \mathrm{~mm} \mathrm{Hg})$, the mean tension devel- 

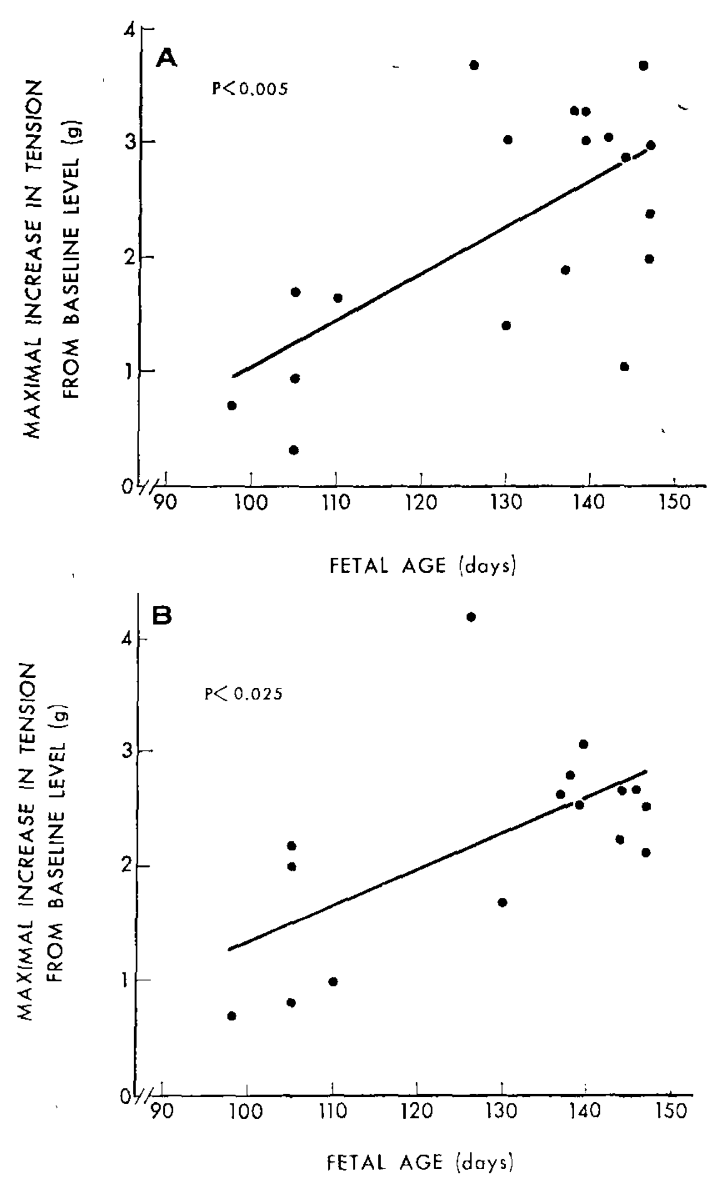

Fig. 2. A. Maximal increase in tension above baseline tension (at $\mathbf{P}_{\mathrm{O}_{2}}$ of $35-45 \mathrm{~mm} \mathrm{Hg}$ ) developed by ductal rings exposed to high $P_{\mathrm{O}_{2}}(450-550 \mathrm{~mm} \mathrm{Hg})$ as a function of fetal gestational age. Linear regression is plotted and $P$ value refers to significance of linear regression. $B$. Maximal increase in tension above baseline tension (at $\mathrm{P}_{\mathrm{O}_{2}}$ of 35 -45 mm $\mathrm{Hg}$ ) developed by ductal rings exposed to low $\mathrm{P}_{\mathrm{O}_{2}}(8-20 \mathrm{~mm} \mathrm{Hg})$ as a function of fetal gestational age. Linear regression is plotted and $P$ value refers to significance of linear regression.

oped was $2.9 \mathrm{~g}$ (range, 1.6-5.5); however, after exposure to higher $\mathrm{Po}_{2}$ levels, subsequent exposure to the same low $\mathrm{PO}_{2}$ produced a significant increase in tension developed (mean, $3.8 \mathrm{~g}$; range, 1.6-7.5) $(P<0.05$; paired $t$ test). On exposure to high $\mathrm{Po}_{2}$, the tension developed on the first exposure (mean, $3.6 \mathrm{~g}$; range, 1.5-4.6) was not significantly different from that developed on a subsequent exposure to the same high $\mathrm{Po}_{2}$ level (mean, 3.8 g; range, 2.2-4.8). The maximal tension developed at high $\mathrm{Po}_{2}$ after several exposures (mean, $3.91 \mathrm{~g}$; range, 2.2-6.7) was not significantly different from that similarly developed at low $\mathrm{Po}_{2}$ (mean, $3.87 \mathrm{~g}$; range, 1.6-7.5).

With increasing $\mathrm{Po}_{2}$, the level at which constriction first developed varied with gestational age. In 5 fetuses of 98- to 110-day gestation, constriction was first noted at $\mathrm{Po}_{2}$ levels of $80-100 \mathrm{~mm} \mathrm{Hg}$, whereas in fetuses older than 125-day gestation, constriction was first noted at $\mathrm{Po}_{2}$ levels of $50-60 \mathrm{~mm} \mathrm{Hg}$. The maximal tension developed was also related to gestational age; younger fetuses developed less tension than did older at both high (Fig. 2A) and low (Fig. 2B) $\mathrm{Po}_{2}$.

With repeated sequential exposure to high and low levels of $\mathrm{Po}_{2}$, the degree of relaxation at the baseline level of $\mathrm{Po}_{2}(35-45 \mathrm{~mm} \mathrm{Hg})$ lessened and tension at this $\mathrm{PO}_{2}$ level gradually increased toward the point of maximal tension (Fig. 3).

The umbilical artery had the same pattern of response. However, increases in tension resulting from changes in $\mathrm{Po}_{2}$ were far less than those developed by the ductus arteriosus at similar $\mathrm{Po}_{2}$ levels. Maximal tension developed by the umbilical artery at high $\mathrm{Po}_{2}$ (mean, $2.3 \mathrm{~g}$; range, 1.4-4.2) was also not significantly different from that developed at low $\mathrm{Po}_{2}$ (mean, 2.1 g; range, 0.9-4.1).

\section{Response to Drugs}

Acetylcholine and Bradykinin. In all 16 instances, acetylcholine increased the tension developed by the ductus arteriosus at all levels of $\mathrm{Po}_{2}$ tested (from mean, $3.38 \mathrm{~g}$; range, $1.9-5.4$ to mean, $3.89 \mathrm{~g}$; range, 2.3-4.7) $(P<0.001)$. This response was similar to that in the perfused ductal preparation [17]. The umbilical artery responded similarly. Bradykinin produced an increase

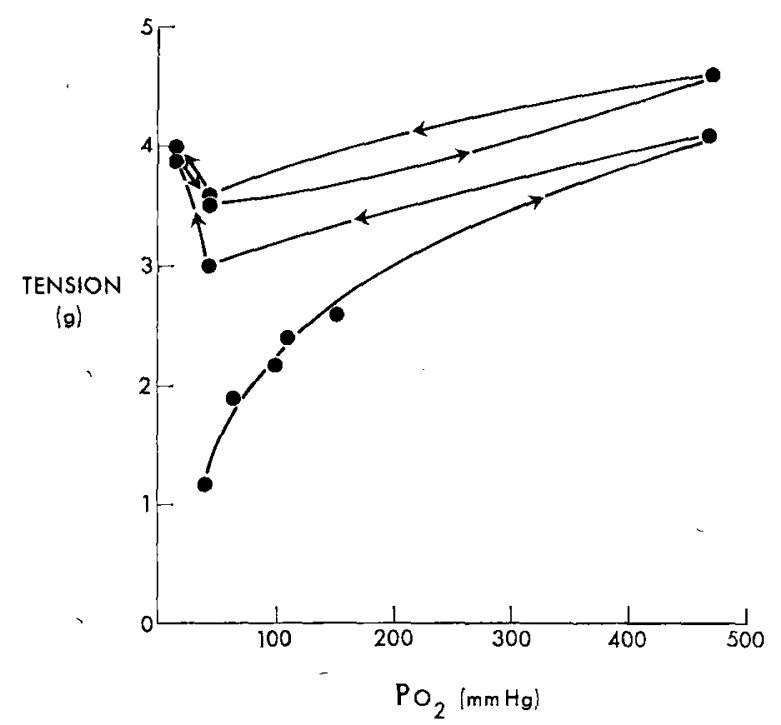

Fig. 3. Effect of repeated sequential exposure to high $\mathrm{P}_{O_{2}}$, then low $\mathbf{P}_{\mathrm{O}_{2}}$, on tension developed by ductal rings. Arrows indicate order of exposure. The baseline tension at $P_{\mathrm{O}_{2}}=40 \mathrm{~mm} \mathrm{Hg}$ increased progressively to approach the maximal tension developed. 
in constriction at high $\mathrm{Po}_{2}$ levels but differed from acetylcholine in that it had no effect at low $\mathrm{PO}_{2}$ levels.

Sympathetic Blockade. Phentolamine had no effect on the ductus arteriosus at any level of $\mathrm{Po}_{2}$, but at high concentration $\left(10^{-3} \mathrm{M}\right)$ it did produce a slight reduction in tension in 3 umbilical arterial preparations. Propanolol had no effect on either ductus arteriosus or umbilical artery at any level of $\mathrm{Po}_{2}$. Concentrations of both drugs were adequate to produce alpha and beta adrenergic blockade.

Parasympathetic Blockade. Addition of atropine to the bath produced relaxation of all ductus arteriosus and umbilical arterial rings at both high and low $\mathrm{PO}_{2}$ levels (Fig. 4). In order to compare the responses to atropine in different preparations, the degree of relaxation was expressed as the percentage decrease of tension from that developed above baseline on exposure to high or low $\mathrm{Po}_{2}$. Dose response curves to atropine by the ductus arteriosus are presented in Figure $5 A$ and by the umbilical artery in Figure $5 B$. The amount of relaxation of the ductus arteriosus produced by similar concentrations of atropine was greater $(P<0.05)$ when constriction had been produced by exposure to high $\mathrm{O}_{2}$ levels than when constricted by low $\mathrm{O}_{2}$. The pattern of response of the umbilical artery was similar to that of the ductus arteriosus but of slightly less degree.

Constriction always recurred when atropine was washed out of the bath by fresh Tyrode's solution at the same $\mathrm{Po}_{2}$. In the presence of atropine, constriction was also renewed by addition of acetylcholine to produce concentrations of $10^{-5}-10^{-3} \mathrm{M}$. When bradykinin was added to the bath to produce concentrations of $100-1000 \mu \mathrm{g} / \mathrm{ml}$ in the presence of atropine, constriction occurred only at the high $\mathrm{Po}_{2}$ level and not at low $\mathrm{Po}_{2}$.

Relaxation of the ductus arteriosus to baseline levels was produced when acetylcholinesterase was added to the bath at both high and low levels of $\mathrm{Po}_{2}$.

When the ductus arteriosus was relaxed at baseline

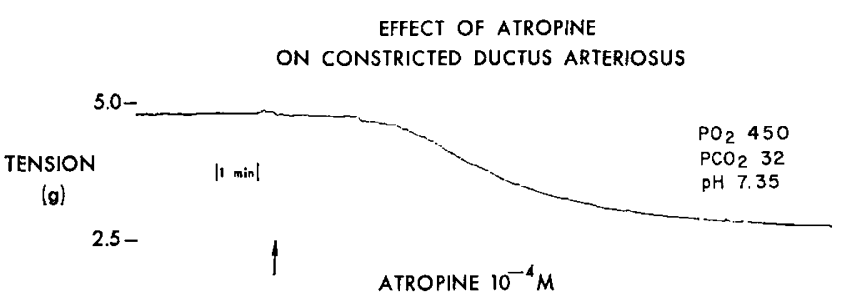

Fig. 4. Actual recording of effect of atropine $\left(10^{-4} \mathrm{M}\right)$ on ductus arteriosus rings from $3800-\mathrm{g}$ fetal lamb maximally constricted by high $\mathrm{P}_{\mathrm{O}_{2}}(450 \mathrm{~mm} \mathrm{Hg})$. Arrow indicates point at which atropine was added.
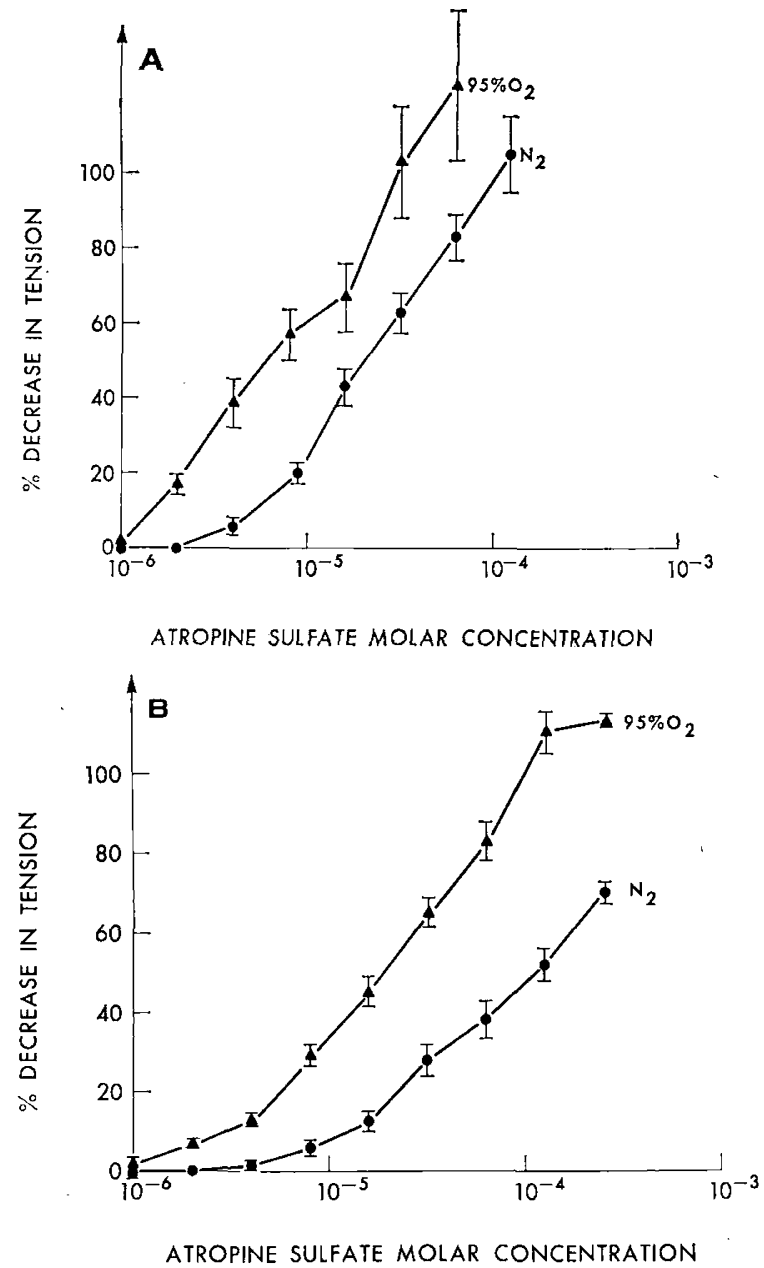

Fig. 5. A. Dose response curves for atropine-induced relaxation of ductus arteriosus rings which had been maximally constricted

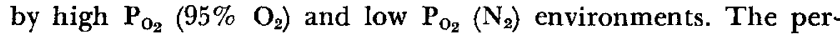
centage decrease in tension from the maximal tension developed is related to concentration of atropine in bath. Mean values and standard errors of the mean are shown. Seven preparations were studied at high $P_{\mathrm{O}_{2}}$ and 5 at low $P_{\mathrm{O}_{2}}$. B. Dose response curves for atropine-induced relaxation of umbilical arterial rings which had been maximally constricted by high $\mathrm{P}_{\mathrm{O}_{2}}\left(\begin{array}{lll}95 \% & \mathrm{O}_{2}\end{array}\right)$ and low $\mathrm{P}_{\mathrm{O}_{2}}\left(\mathrm{~N}_{2}\right)$ exposure. The percentage decrease in tension from the maximal tension developed is related to concentration of atropine in bath. Mean values and standard errors of the mean are shown. Three preparations were studied at high $\mathbf{P}_{\mathrm{O}_{2}}$ and 5 at low $\mathrm{P}_{\mathrm{O}_{2}}$.

$\mathrm{Po}_{2}$ (35-45 mm $\mathrm{Hg}$ ), edrophonium produced an increase in tension. After maximal tension had developed, reduction in $\mathrm{Po}_{2}$ to low level produced no further constriction but increase in $\mathrm{Po}_{2}$ to $450-550 \mathrm{~mm}$ $\mathrm{Hg}$ produced a small additional increase in tension.

\section{Discussion}

The importance of $\mathrm{O}_{2}$ in constriction of the ductus arteriosus has been appreciated for several decades 
[13]. However, the exact pattern of response of the ductus arteriosus to changing levels of $\mathrm{Po}_{2}$ had not been carefully delineated. Recently [17] we showed the constrictor effect on the ductus arteriosus of fetal lambs of increasing $\mathrm{Po}_{2}$ from 15 to $600 \mathrm{~mm} \mathrm{Hg}$ and demonstrated that response was related to gestational age. Ductus arteriosus in lambs under 125-day gestation showed a minimal response to $\mathrm{O}_{2}$, yet it had the capability to constrict with acetylcholine or norepinephrine. These observations help to explain the findings which showed that the ductus arteriosus isolated from human fetuses of 10- to 20-wk gestation failed to constrict when exposed to $\mathrm{O}_{2}$, but did respond to catecholamines, acetylcholine and bradykinin $[1,5,6,16]$. In our previous study, response to increasing $\mathrm{Po}_{2}$ was curvilinear, and in the term fetus the initial level of $\mathrm{Po}_{2}$ to which the ductus arteriosus responded was in the range of 60 to $80 \mathrm{~mm} \mathrm{Hg}$. However, sensitivity of the method was quite low since the degree of ductal constriction was assessed by measuring the pressure drop across a perfused ductus. In the present studies, response to increasing $\mathrm{Po}_{2}$ was again curvilinear, but the initial level of $\mathrm{Po}_{2}$ to which the ductus arteriosus of the term fetal lamb responded was $50-60 \mathrm{~mm} \mathrm{Hg}$.

In the isolated ductus arteriosus in the organ bath it was also technically possible to develop $\mathrm{Po}_{2}$ levels consistently lower than those achieved in the perfused ductal preparation. Response of the ductus arteriosus below $\mathrm{PO}_{2}$ levels of $35 \mathrm{~mm} \mathrm{Hg}$ was of considerable interest in that constriction occurred when $\mathrm{Po}_{2}$ was lowered to $8-20 \mathrm{~mm} \mathrm{Hg}$. On initial exposure to low $\mathrm{Po}_{2}(8-20 \mathrm{~mm} \mathrm{Hg})$, the amount of tension developed by the ductus arteriosus was not as great as after initial exposure to high $\mathrm{Po}_{2}$. However, after repeated exposures of an individual ductus arteriosus to different $\mathrm{PO}_{2}$ levels, the maximal tensions developed at both high and low $\mathrm{Po}_{2}$ levels were similar.

The observation that the ductus arteriosus does not relax to its original baseline tension at $\mathrm{Po}_{2}$ of $35-45$ $\mathrm{mm} \mathrm{Hg}$ after repeated constriction in high or low $\mathrm{Po}_{2}$ ranges is difficult to explain. It is possible that this results from a persistent change in the constrictor muscle. However, this does not seem likely since relaxation could be produced with atropine. It seemed likely therefore that it could result from accumulation of an active mediator in the ductal tissue, or from depletion of an antagonist or a substance which degrades the mediator.

The effects of pharmacologic agents, particularly sympathomimetic and parasympathomimetic drugs, on the ductus arteriosus have been extensively studied in different species $[1,5,6,14,16,17,22]$. These studies have demonstrated that norepinephrine, epinephrine, and acetylcholine constrict the ductus arteriosus. This has raised the question as to the possible role of the autonomic nervous system in constriction of the ductus arteriosus in response to changes in $\mathrm{Po}_{2}$.

Through use of fluorescent staining techniques, sympathetic nerve fibers have been demonstrated in the outer third of the medial muscle layer of the ductus arteriosus in 10- to 20-wk human fetuses [1,6], fetal lambs [12], and fetal guinea pigs [15]. In view of the presence of networks of sympathetic nerves and the fact that tyramine produces a contractile response in the ductus arteriosus, Aronson et al. [1] suggested that adrenergic mechanisms were important in normal ductal closure. However, Kovalčik et al. [15] have recently demonstrated that ductus arteriosus obtained from guinea pigs treated with reserpine still constricts markedly on exposure to $\mathrm{O}_{2}$. Our studies with isolated lamb ductus arteriosus confirm the original observation of Kovalčik [14] that response to high levels of $\mathrm{PO}_{2}$ is not influenced by either specific alpha or beta adrenergic blockade. Furthermore we have shown that constriction of the ductus arteriosus in a low $\mathrm{O}_{2}$ environment is also not prevented by specific adrenergic blockade.

Investigators who have examined responses of the ductus arteriosus have been impressed by the fact that acetylcholine produces a more significant contraction than any other drug tested, e.g., norepinephrine, epinephrine, 5-hydroxytryptamine, and bradykinin. Human fetal ductus arteriosus at 10 - to 20 -wk gestation is also constricted by acetylcholine, but histologic studies have failed to reveal any significant number of cholinergic nerve fibers [1]. On the basis of these observations and Kovalčik's data [14] that atropine had no influence on isolated ductus arteriosus of fetal lamb, the possible importance of acetylcholine in the $\mathrm{O}_{2}$ response of the ductus arteriosus previously was not seriously considered.

Our studies show conclusively that atropine does, in fact, completely reverse constriction of the ductus arteriosus on exposure to high $\mathrm{Po}_{2}$ environment. However, the degree of relaxation was less prominent at low $\mathrm{O}_{2}$ with similar concentrations of atropine. This difference cannot be explained. Elution of atropine from the bath resulted in a return to the constricted state. Relaxation is not a toxic effect of the atropine on the ductus arteriosus muscle, as is confirmed by the fact that addition of acetylcholine overcomes the relaxant effect of atropine.

In an attempt to provide more conclusive evidence 
that constriction with high or low $\mathrm{O}_{2}$ was specifically related to acetylcholine release, and that the antagonistic effect of atropine was specific, we demonstrated that acetylcholinesterase also relaxed constricted ductus arteriosus at both $\mathrm{Po}_{2}$ levels. Additional evidence in support of the fact that the constrictor effects of changes in $\mathrm{O}_{2}$ environment are mediated by the release of acetylcholine are afforded by the studies using edrophonium, a cholinesterase inhibitor. Upon addition of edrophonium to the organ bath when the ductus arteriosus was relaxed in an $\mathrm{O}_{2}$ environment of 35-40 $\mathrm{mm} \mathrm{Hg}$, constriction occurred; afterwards, elevation of $\mathrm{Po}_{2}$ to $450 \mathrm{~mm} \mathrm{Hg}$ produced only a minor degree of further constriction.

Dependence of ductal constriction on gestational development may also be explained by the pattern of development of cholinergic nerve endings in the ductus arteriosus. As mentioned above, human fetal ductus arteriosus between 10- and 20-wk gestation does not contain cholinergic nerve endings or significant quantities of cholinesterase. Ductus arteriosus at this stage of development does not respond to $\mathrm{O}_{2}$ but will constrict following direct exposure to acetylcholine. Ductus arteriosus of fetal puppy at term [18] as well as that of fetal lamb at term [21] have been shown to contain large quantities of cholinesterase. It has been suggested by Silva and Ikeda [21] that demonstration of cholinesterase by histochemical staining techniques indicates the presence of cholinergic nerves in the ductus arteriosus. The very active constriction of the ductus arteriosus of late gestation fetal lamb on exposure to changes in $\mathrm{O}_{2}$ environment could therefore be related to a mechanism promoting release of acetylcholine.

The umbilical artery of the lamb shows identical qualitative responses to changes in $\mathrm{O}_{2}$ environment and to atropine, as does the ductus arteriosus. We have not examined the umbilical artery in the region from which the rings were obtained by histochemical techniques for cholinergic nerve endings or acetylcholinesterase activity. However, it is generally thought that umbilical vessels do not have a nerve supply, but this requires further confirmation. If, in fact, the umbilical artery does not have a nerve supply, then it is possible that acetylcholine is being released locally from nonneuronal tissue and is exerting a direct local physiological effect in response to changes in $\mathrm{O}_{2}$ environment.

The fact that acetylcholine produced additional constriction over and above that produced by changes in $\mathrm{Po}_{2}$ at each level over the whole range of $\mathrm{O}_{2}$ environment studied $(8-550 \mathrm{~mm} \mathrm{Hg}$ ), whereas bradykinin was only effective in the higher $\mathrm{Po}_{2}$ ranges, suggests that the mechanism for constriction by bradykinin was different from that for acetylcholine. However, there may be some interrelation between the responses inasmuch as, when the ductus was relaxed by atropine at high $\mathrm{PO}_{2}$ levels, much larger concentrations of bradykinin were required to produce constriction than were necessary in the absence of atropine.

It would thus appear that there are several physiologic mechanisms which may be active in the production of constriction of the ductus arteriosus. The most effective of these is an increase in $\mathrm{Po}_{2}$, the effect of which is mediated by local release of acetylcholine. Sympathetic stimulation may also constrict the ductus arteriosus by either direct local release of catecholamines or by release into the general circulation. Similarly, systemic release of bradykinin at birth may also play a role in postnatal ductal constriction.

\section{Summary}

In fetal lambs constriction of the ductus arteriosus and umbilical artery is produced by both increasing and decreasing $\mathrm{PO}_{2}$ from a baseline level of $35-45 \mathrm{~mm} \mathrm{Hg}$. Maximal constriction increases with increasing gestational age. Atropine and acetylcholinesterase reverse this constriction whereas acetylcholine enhances it. Edrophonium increases tension above baseline. Sympathetic blockade has no effect on the oxygen response.

These studies suggest that the constrictor effect of oxygen is mediated by release of acetylcholine.

\section{References and Notes}

1. Aronson, S., Gennser, G., Owman, C. H., and Sjöberc, N.-O: Innervation and contractile response of the human ductus arteriosus. Europ. J. Pharmacology, 11: 178 (1970).

2. Assali, N. S., Morris, J. A., Smith, R. W., and Manson, W. A.: Studies on the ductus arteriosus circulation. Circulation Res., 13: 478 (1963).

3. Barcroft, J.: Researches on Pre-natal Life. (Blackwell, Oxford, 1946).

4. Bor, I., AND GUNTheroth, W. G.: In vitro response to oxygen of human umbilical arteries and of animal ductus arteriosus. Canad. J. Physiol. Pharm., 48: 500 (1970).

5. Boréus, L. O.: Pharmacology of the human fetus: dose-effect relationship for acetylcholine during ontogenesis. Biol. Neonat., 11: 328 (1967).

6. Boréus, L. O., Malmfors, T., McMurphy, D. M., and Olson, L.: Demonstration of adrenergic receptor function and innervation in the ductus arteriosus of the human fetus. Acta Physiol. Scand., 77: 316 (1969).

7. Born, G. V. R., Dawes, G. S., Mott, J. C., And Rennick, B. R.: The constriction of the ductus arteriosus caused by oxygen and by asphyxia in newborn lambs. J. Physiol. (London), 132 : 304 (1956).

8. Dawes, G. S.: Changes in the circulation at birth. Anaesthesiol., 26: 522 (1965). 
9. Eltherington, L. G., Stoff, T., Hughes, T., and Melmon, K. L.: Constriction of human umbilical arteries. Interaction between oxygen and bradykinin. Circulation Res., 22: 747 (1968).

10. Heymann, M. A., Rudolph, A. M., Nies, A. S., and Melmon, K. L.: Bradykinin production associated with oxygenation of the fetal lamb. Circulation Res., 25: 521 (1969).

11. Hornblad, P. Y.: Experimental studies on closure of the ductus arteriosus utilizing whole body freezing. Acta Paediat. Scand., Suppl. 190: 1 (1969).

12. IKEDA, M.: Adrenergic innervation of the ductus arteriosus of the fetal lamb. Experientia, 26: 525 (1970).

13. Kennedy, J. A., and Clark, S. L.: Observations on the physiological reactions of the ductus arteriosus. Amer. J. Physiol., 136: 140 (1942).

14. Kovalčı, V.: The response of the isolated ductus arteriosus to oxygen and anoxia. J. Physiol. (London), 169: 185 (1963).

15. KovalčıIK, V., KrišKa, M., AND DoležEL, S.: The problem of adrenergic innervation of the ductus arteriosus in the guineapig foetus and its role in the mechanism of constriction. Physiologia Bohemoslovace, 18: 401 (1969).

16. McMurphy, D. M., ANd Boréus, L. O.: Studies on the pharmacology of the perfused human fetal ductus arteriosus. Amer. J. Obstet. Gynecol., 109: 937 (1971).

17. McMurphy, D. M., Heymann, M. A., Rudolph, A. M., and Melmon, K. L.: Developmental changes in constriction of the ductus arteriosus: responses to oxygen and vasoactive agents in the isolated ductus arteriosus of the fetal lamb. Pediat. Res., 6: 231 (1972).

18. Molnar, J. J., Mesel, E., Golinko, R. J., and Rudolph, A. M.: Structure, histochemistry and physiology of ductus arteriosus in the dog. J. Histochem. Cytochem., 10: 667 (1962).

19. Moss, A. J., Emmanouilides, G. C., Adams, F. H., and Chunng, K.: Response of the ductus arteriosus and pulmonary and systemic arterial pressure to change in oxygen environment in newborn infants. Pediatrics, 33: 937 (1964).

20. Reis, R. L., And Anderson, R. P.: Constriction of the ductus arteriosus. Experimental observations in the newborn lamb. J. Surg. Res., 4: 356 (1964).
21. Silva, D. G., AND IKEDA, M.: Ultrastructural and acetylcholinesterase studies on the innervation of the ductus arteriosus, pulmonary trunk and aorta of the fetal lamb. J. Ultrastructure Res., 34 : 358 (1971).

22. Smyth, R. W., Morris, J. A., Assali, N. S., and Beck, R.: Effects of chemical mediators on the pulmonary and ductus arteriosus circulation in the fetal lamb. Amer. J. Obstet. Gynecol., 89: 252 (1964).

23. Pontocaine, Winthrop Laboratories, New York, N.Y.

24. Phibbs \& Bird, Inc., Richmond, Va.

25. Model FT 03C, Grass Instruments Inc., Quincy, Mass.

26. Model 5A, Grass Instruments Inc., Quincy, Mass.

27. Radiometer A/S, Copenhagen NV, Denmark.

28. Miochol, Smith, Miller \& Patch Inc., New York, N.Y.

29. Synthetic Bradykinin, Calbiochem, Los Angeles, Calif.

30. Regitine, Ciba Pharmaceutical Products, Inc., Summit, N.J.

31. Inderal, Ayerst Laboratories, Inc., New York, N.Y.

32. Atropine sulfate, Invenex Pharmaceuticals, San Francisco, Calif.

33. Harleco, Philadelphia, Pa.

34. Tensilon, Hoffman LaRoche, Inc., Nutley, N.J.

35. We thank Miss Christine Mueller and Mr. Les Williams for technical assistance.

36. Supported by Program Project Grants nos. HL06285 and HL09964 from the National Heart and Lung Institute and Grant no. GM01791 from the National Institute of General Medical Sciences, National Institutes of Health.

37. Present address of Dr. I. Oberhänsli-Weiss is: UniversitatsKinderklinik Zurich, Steinwiestrasse 75, CH 8032, Zurich, Switzerland.

38. Dr. M. A. Heymann is the recipient of Research Career Development Award no. HD35398 from the National Institute of Child Health and Human Development, National Institutes of Health.

39. Requests for reprints should be sent to: Michael A. HexManN, M.D., Cardiovascular Research Institute, University of California San Francisco, San Francisco, California 94122 (USA).

40. Accepted for publication April 5, 1972. 